\title{
Fatigue design of tubular bracings in steel and composite bridges
}

\author{
L. Gölz \& U. Kuhlmann \\ Institute of Structural Design, University of Stuttgart, Stuttgart, Germany
}

\begin{abstract}
For sustainable and economical infrastructures such as steel and composite bridges a practice-oriented and fatigue-suitable design is crucial. Cross girder bracings or box girder diaphragms are often realised with tubular elements especially with circular hollow sections (CHS) including a welded connection between the slitted tubular element and the gusset plate. The gusset plate welding at the end of the slit of the tube is the critical fatigue spot. For the currently different design variants used in bridge construction with basically different notches there is no clear rule given regarding the detail category by the standards EN 1993-2 or EN 1993-1-9. This paper summarises the results of the AiF-DASt research project on three different fatigue design solutions for tubular bracings in steel and composite bridges. An insight on the practice-oriented design, the benefits for the execution and manufacturing as well as the results of the experimental fatigue tests are given.
\end{abstract}

\section{MOTIVATION}

In steel and composite bridge construction, for medium spans the superstructure is often designed as a box girder section due to the high torsional stiffness. In order to retain the shape constancy of the cross-section inside the box girder, a truss-framed solution is regularly realised, see Figure 1. For wider bridge cross-sections, the cantilevered slabs are typically supported by diagonal bracings outside of the box girder. For these two functions, tubular crosssections are mostly used since circular hollow sections are preferred for trussed beams due to the reduced risk of buckling in combination with isotropic stiffness.

This type of joint with slitted tubes at the gusset plates that is usually used in bridge crosssections inside or outside of box girders is under discussion due to critically assessed fatigue behaviour in some cases. In bridge construction, various design variants are currently used resulting from the unspecific requirements and rules in the standards EN 1993-2 (2005) or EN 1993-1-9 (2005). Those variants have fundamentally different notches and therefore projectspecific individual case studies are necessary to prove the fatigue strength for the current case. Mostly the fatigue behaviour has just been proven by numerical investigations, but not by fatigue experiments - except for the Rinsdorf Bridge in Germany. In those investigations some cases showed significantly worse fatigue strengths compared with the detail category 71 given in EN 1993-1-9 (2005) for the connection with holes at the end of the slit, see Figure 2. This detail category 71 has not been validated by fatigue experiments and the description in the standard is incomplete. Reducing however as a consequence the detail category in general on the safe side to 36 would lead to extremely unfavourable dimensioning and almost no longer feasible design thickness ratios. When looking at steel and composite bridges with box girder constructions that are currently under construction or have recently been completed, this topic proves to be of high importance. There is a fundamental need for research regarding the fatigue resistance of the different design variants of joints between circular hollow sections and plates. 

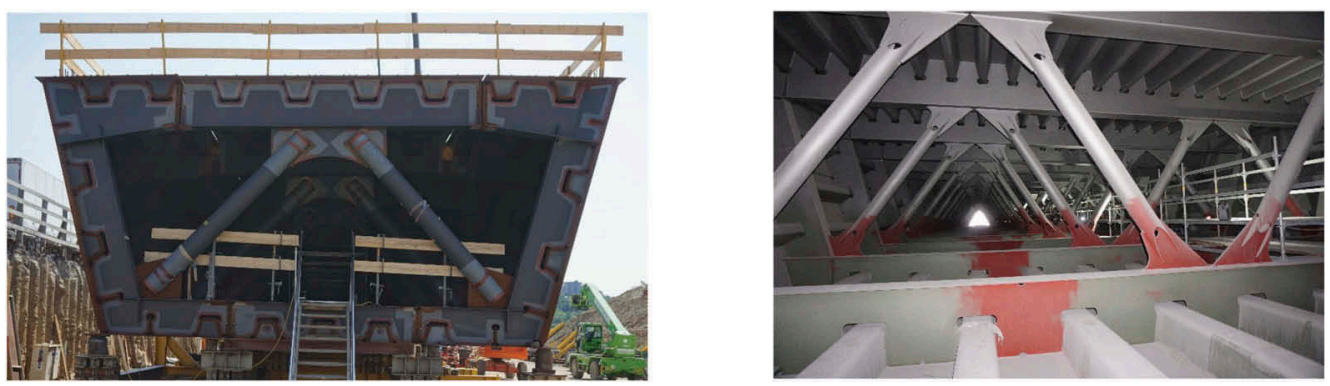

Figure 1. Design variants of tubular bracings inside of box girders of the German bridges Heidingsfeld (left) and Schierstein (right) (Kuhlmann \& Gölz 2021).

\begin{tabular}{|c|c|c|c|c|}
\hline 71 & $\alpha \leq 45^{\circ}$ & $\gamma$ & 2) Tube-plate joint, & 2) $\Delta \sigma$ computed in tube. \\
\hline 63 & $\alpha \geq 45^{\circ}$ & 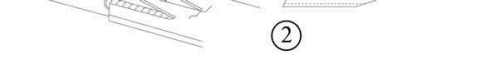 & welded to plate. & $\begin{array}{l}\text { weld should be verified } \\
\text { using Table } 8.5 \text {, detail } 8 \text { ). }\end{array}$ \\
\hline
\end{tabular}

Figure 2. Extract from EN 1993-1-9 (2005) - Table 8.6 Hollow sections $(\mathrm{t} \leq 12.5 \mathrm{~mm})$.

\section{STATE OF THE ART}

\subsection{Normative rules}

The current fatigue design of tubular bracings provided by EN 1993-2 (2005) and EN 19931-9 (2005) follows the nominal stress concept. For diagonals in bridges, the detail category 71 is given in EN 1993-1-9 (2005) with a restriction of the tube wall thickness ( $\mathrm{t} \leq 12.5 \mathrm{~mm})$, see Figure 2. A case differentiation is made depending on the angle of the chamfered hollow section, but no information is given on the effect of other geometric dimensions, such as the geometry of the cut-out, the shape of the gusset plate and the type of welding. Also, the location of the sealing plate (exterior or interior), that is usually required for corrosion protection inside or outside box girders, is not further specified. The location of the crack initiation also is questionable, since it is shown in Figure 2 in the gusset plate, but the stress range $\Delta \sigma$ has to be calculated for the hollow section.

A first basis for EN 1993-1-9 (2005) has been developed within the revision of the German steel design standard for the unpublished DIN 18800 - Part 6 (unpubl.) in connection with the S-N curves catalogue for hollow sections (Mang et al. 1987), which also contains international fatigue test results. In this context design recommendations for various notch details made of hollow sections have been prepared. Based on the design recommendations acc. to Mang et al. (1987), the detail categories were further classified in the Steel Construction Handbook (1993) by the type of welding.

Comparing the current valid standards and rules such as Eurocode (EN 1993-1-9 2005), IIW (Hobbacher 2014), British Standard (BS 7608 2014) and DNV (DNV GL-RP-C203 2016), obviously different requirements and approaches are used to determine the detail category. This underlines that there is a need for further research to identify the relevant parameters for the fatigue strength of joints between hollow sections and plates.

\subsection{Previous investigations on tubular bracings}

Due to the different approaches for the evaluation of detail categories in the standards (EN 1993-1-9 2005, Hobbacher 2014, British Standard 7608 2014, DNV GL-RP-C203 2016), the existing database of the fatigue tests of Zirn (1975), Baptista et al. (2017) and Hanswille \& 
a)

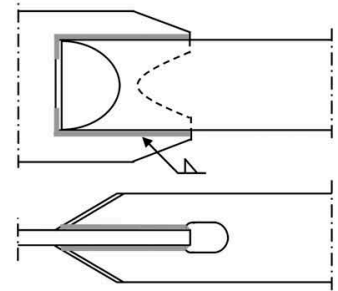

b)

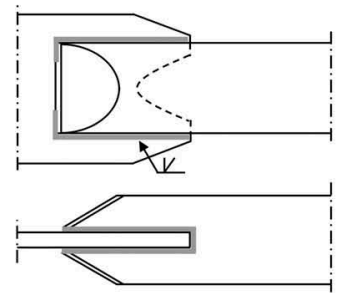

c)

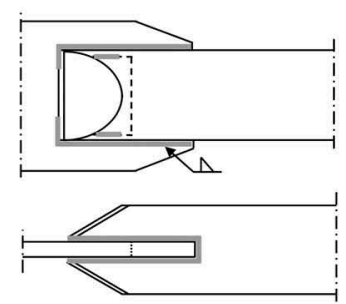

Figure 3. Recommendations from Baptista et al. (2017) for hollow-section-to-plate joints with detail category 56.

Schubart (2017) was statistically re-evaluated in the AiF-DASt-Project "Practice-oriented design of tubular bracings in steel and composite bridges" (Kuhlmann \& Gölz 2021). The aim is to evaluate the influences on the fatigue strength, e.g. chamfering of the hollow section, shape of gusset plate, type of welding, gusset plate thickness, material and the influence of cut-outs at the end of the slit in the hollow section.

Since extensive investigations on statistical evaluation methods were carried out in another AiF-DASt-FOSTA research project (Feldmann et al. 2020), the existing database was reevaluated in Kuhlmann \& Gölz (2021) acc. to Drebenstedt \& Euler (2018). This uniform statistical evaluation method according to EN 1990 (2002) and Background Document 9.01 (ECCS TC6 No.140 2018) by using the prediction interval (Holický 2005) allows the individual design details to be compared to each other.

The following results regarding the fatigue strength of tubular bracings have been derived from Zirn (1975): improvement by chamfering of the hollow section, improvement by semicircular shaped gusset plate, no influence of the material, full penetration welds have a higher fatigue strength than fillet welds - except for details with holes at the end of the slit.

As already mentioned in Baptista et al. (2017), the re-evaluation of the fatigue test results shows that only the type of welding has a large influence on the fatigue strength and all the other parameters have in fact a positive influence on the fatigue strength, but the effects are relatively small and may be even neglected. In Baptista et al. (2017) fatigue experiments and numerical investigations have been carried out. Based on this, recommendations are given for the investigated design details: a) single slit with elongated hole and fillet welds, b) single slit with full penetration welds and c) double slit with fillet welds, shown in Figure 3 with detail category 56.

In Kuhlmann \& Gölz (2021) design variants of Zirn (1975), Baptista et al. (2017) and Hanswille \& Schubart (2017) with slitted, chamfered hollow sections and full penetration welds were statistically re-evaluated and the fatigue strengths were compared. Although the test specimens differed in their geometric conditions like tube diameter, wall thickness, pool backing, gusset plate thickness and sealing plates and in their type of loading, the deviation in the evaluated characteristic fatigue strengths was not remarkable. As this design variant is similar to those in bridge practice, the classification of diagonal bracings in detail category 50 is much more realistic than the current detail category 71 acc. to EN 1993-1-9 (2005), which seems to be not conservative.

\section{EXPERIMENTAL INVESTIGATIONS ON TUBULAR BRACINGS}

\subsection{Introduction}

In the AiF-DASt research project (Kuhlmann \& Gölz 2021), for three design variants experimental and numerical investigations are carried out and notch effects are derived. The aim of the project is to achieve economically and technically improved constructional details, a wider range of application by normatively secured design solutions, practical dimensioning and 
design recommendations with optimised production as well as durable bridge construction to minimise cost-intensive maintenance and to avoid traffic closures. The analysis of existing test results, see section 2.2, showed that the weld around the gusset plate tip is the critical notch for details without cut-out at the end of the slit. The overall geometry of the three designed test specimens was adapted to real examples from bridge construction practice.

\subsection{Fatigue experiments}

The fatigue tests for the specimens shown in Figure 4 were carried out at the Material Testing Institute of the University of Stuttgart. Twenty-four specimens were tested with a specimen length of about $2 \mathrm{~m}$, eight tests per connection type at different stress levels from $50-225$ $\mathrm{MPa}$ with stress ratio $\mathrm{R}=0.1$ and frequencies of $1.2-9.5 \mathrm{~Hz}$. The diameter of the circular hollow section (CHS) tube was $168.3 \times 8 \mathrm{~mm}$, the thickness of the semi-circular shaped gusset plate was $t_{p}=20 \mathrm{~mm}$, the thickness of the sealing plates $t_{s}=10 \mathrm{~mm}$ and the thickness of the welds $\mathrm{a}_{\mathrm{w}}=8 \mathrm{~mm}$ with weld lengths $1_{\mathrm{w}}=265 \mathrm{~mm}$. The materials of the tube, gusset plate and sealing plate were $\mathrm{S} 355 \mathrm{~J} 2 \mathrm{H}$ and $\mathrm{S} 355 \mathrm{~J} 2+\mathrm{N}$.

Series 1 is adapted to the Schierstein Bridge, Germany regarding its dimensioning and choice of geometry. The geometry of the hole at the end of the slit is based on the numerical investigations of Baptista et al. (2017). The advantage of this design variant is that there is the possibility to compensate tolerances in the longitudinal direction of the tube without increasing the root gap. Also better conditions for welding and post-weld treatment are guaranteed compared to Series 2 and 3. When the crack is initiated at the edge of the hole, it is visible and can easily be detected. A disadvantage of this design variant is that it can only be used inside of the box girders or just for the lower joint of the diagonal outside box girders, as water can accumulate on the upper interior sealing plate. In this series, the type of welding is not the decisive parameter for the fatigue strength because the fatigue crack is not initiated from the weld, rather the geometry and surface quality of the cut-out is decisive.

For Series 2, a production-optimised and practical design was chosen with a straight sealing plate and a HY-weld with fillet weld. The exterior sealing plate ensures that the connection may also be used outside of the box girder. A disadvantage is that tolerance compensation in the longitudinal direction is not possible and that fatigue cracks at the gusset plate tip weld are difficult to detect. Compared to the HV-weld with pool backing in Series 3, the HY-weld provides a more practical design, as no ultrasonic testing is required, and the inside of the tube does not have to be accessible. This is also an alternative solution for tubes with small diameters, where pool backing is not possible. The tubes can already be delivered with sealing plates to the site, which is a great advantage for prefabrication. In Series 2, the tube and the gusset plate were formed with $45^{\circ}$ chamfers in the area of the critical weld at the gusset plate tip in order to produce a shape that is similar to the rounding in Series 3. The $45^{\circ}$ chamfers are an economical alternative for production purposes to complete rounding.

The third connection variant with an inclined sealing plate and a full penetration weld with pool backing, Series 3, is a notch-optimised, fatigue-resistant solution that involves higher production costs compared to Series 2. It was designed on the basis of the German RiZ-ING guideline drawings (BASt 2018) and the investigations carried out for the Rinsdorf Bridge

Series 1

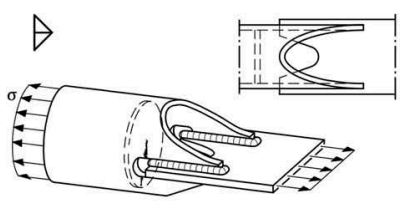

Series 2

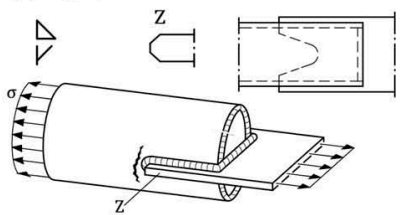

Series 3

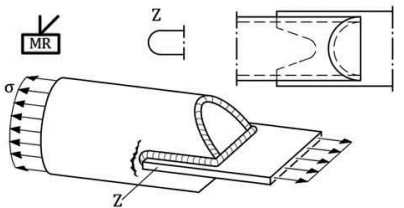

Figure 4. Overview of test specimens of the AiF-DASt research project (Kuhlmann \& Gölz 2021) acc. to prEN 1993-1-9 (2020). 
(Hanswille \& Schubart 2017). The disadvantages are analogous to Series 2. The advantage of the inclined sealing plate is that the inside of the tube is accessible. Due to this, the possibility is given to provide the necessary pool backing and to check the weld. The exterior sealing plate could only be welded to the tube after the joint between the hollow section and the plate due to inside quality assurance of the full penetration weld, which has a disadvantageous effect on prefabrication compared with Series 2. In the curved area of the gusset plate tip, no pool backing can be executed due to production possibilities. To achieve a notch-less and fatigue-resistant design, the gusset plate tip and the end of the slit in the tube have been rounded.

Based on the fatigue tests in Kuhlmann \& Gölz (2021), a comparison between the practical (Series 2) and the notch-optimised (Series 3) design is carried out.

\subsection{Results}

As already explained in section 2.2, the fatigue tests are evaluated with the prediction interval and a fixed slope of $m=3$. The failure criterion was defined as the complete fracture of the specimen. The nominal stresses are calculated in the tube gross section for Series 2 and 3, for Series 1 the net hollow section is used with $A_{\text {net }}=A-2 \cdot d_{H}$ where $d_{H}$ is the hole diameter at the end of the slit.

According to Figure 5, the characteristic fatigue resistances for fixed slopes with $\mathrm{m}=3$ are for Series 1: $\Delta \sigma_{C}=43.5 \mathrm{~N} / \mathrm{mm}^{2}$, for Series 2: $\Delta \sigma_{C}=50.8 \mathrm{~N} / \mathrm{mm}^{2}$ and for Series 3: $\Delta \sigma_{C}=56.9$ $\mathrm{N} / \mathrm{mm}^{2}$.

See Table 1 for typical crack patterns of the three different design variants. As expected, in Series 1 the crack was initiated at the cut-out. The interior sealing plate was not the decisive notch in this design variant and furthermore there were no other cracks located in the gusset plate near the longitudinal fillet weld. For Series 2 and 3, the welding at the gusset plate tip was the critical fatigue spot and the crack initiation was from the inside of the tube. There were also no other cracks visible in the gusset plate near the sealing plates or the longitudinal welds.

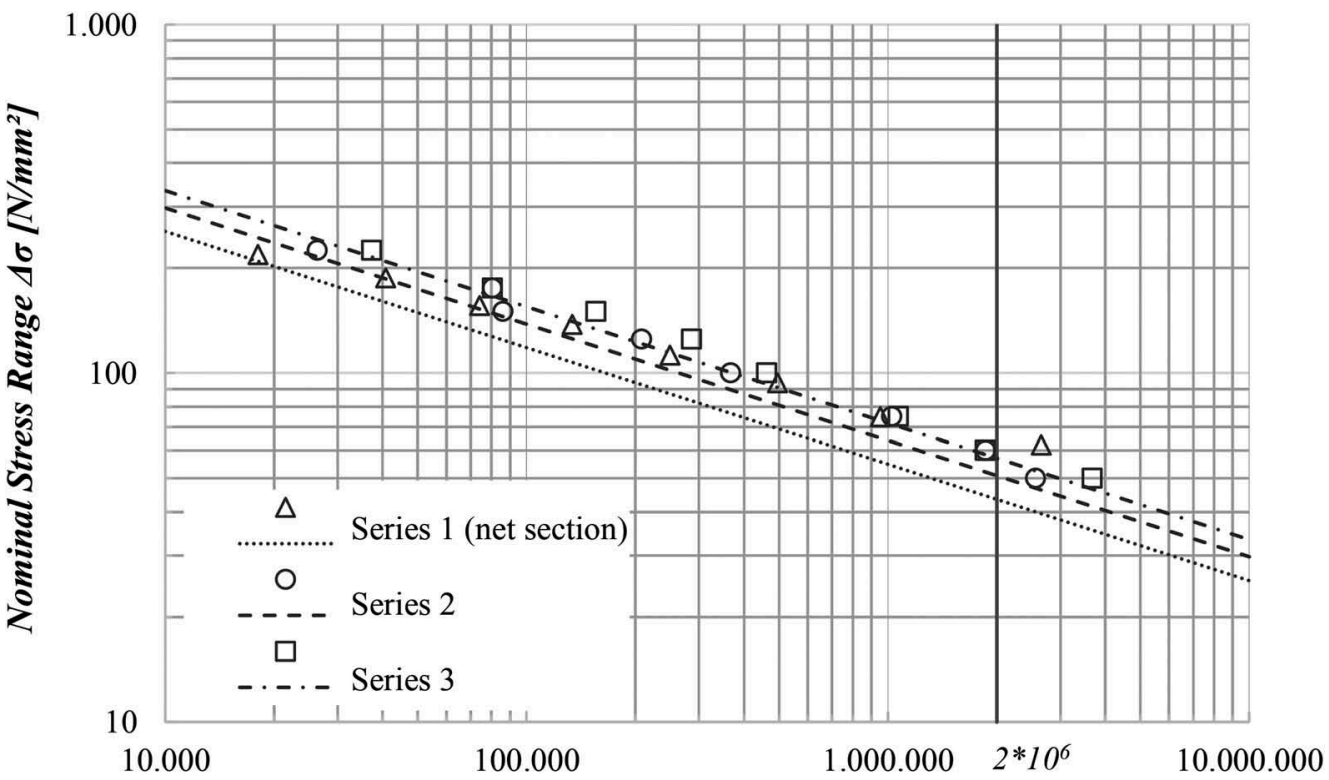

Number of Cycles $N$ [-]

Figure 5. Characteristic fatigue resistance curves of test results subject to nominal stress range evaluated with fixed slope $\mathrm{m}=3$ (Kuhlmann \& Gölz, 2021). 


Series 1

\section{CONCLUSIONS}

Based on the fatigue test results from Kuhlmann \& Gölz (2021) and the research about previous fatigue tests from Zirn (1975), Baptista et al. (2017) and Hanswille \& Schubart (2017) proposals and recommendations for the next generation of the Eurocode prEN1993-1-9 (2020) can be given. For design variants without cut-outs at the end of the slit, the type of welding is the decisive parameter for the fatigue resistance. For details with full penetration welds and pool backing, that therefore require a chamfered hollow section for quality assurance of the weld root, detail category 56 is recommended. For HY-welds with fillet welds and chamfered or straight hollow sections detail category 50 is recommended. For a design variant with a cut-out at the end of the slit and with a chamfered hollow section having the same length as the longitudinal double fillet weld, detail category 45 is recommended. For a similar design variant with cut-outs, Baptista et al. (2017) recommended detail category 56. The remarkable difference between these two variants from Kuhlmann \& Gölz (2021) and Baptista et al. (2017) is the ratio between the length of the chamfered hollow section and the longitudinal fillet weld. This and other geometric parameters need to be investigated in further research.

\section{ACKNOWLEDGMENTS}

The work presented has been carried out as part of a research project. This project 20452 (Kuhlmann \& Gölz 2021) of the research association DASt is financed by AiF, within the development programme for industrial community research and development IGF from the Federal Ministry of Economic Affairs and Energy BMWi based on a decision of the German Bundestag.

Special thanks go to "AG der Dillinger Hüttenwerke" and "Vallourec Deutschland GmbH" for provision of materials and to "Plauen Stahl Technologie GmbH", "Max Bögl Bauservice $\mathrm{GmbH} \& \mathrm{Co}$. KG" and "MCE GmbH" for the fabrication of the test specimens.

\section{REFERENCES}

Baptista, C., Kannuna, S., Pedro, J. O. \& Nussbaumer, A. 2017. Fatigue behaviour of CHS tubular bracings in steel bridges. International Journal of Fatigue 96, 126-141.

BASt - Bundesanstalt für Straßenwesen. 2018. Konstruktions- und Bemessungshinweise für Stahl- und Stahlverbundbrückenkonstruktionen - German RiZ-ING guideline drawings. draft.

BS 7608:2014+A1:2015 - Guide to fatigue design and assessment of steel products. BSI.

DNV GL-RP-C203: 2016. Fatigue design of offshore steel structures. Recommended Practice.

Drebenstedt, K. \& Euler, M. 2018. Statistical Analysis of Fatigue Test Data according to Eurocode 3. In: 9th International Conference on Bridge Maintenance, Safety and Management IABMAS, Melbourne.

ECCS TC6 No.140. 2018. Background Information on Fatigue Design Rules - Statistical Evaluation. 2nd edition. Technical Committee 6 Fatigue and Fracture. 
EN 1990:2002. Eurocode 0: Basis of structural design.

EN 1993-1-9:2005. Eurocode 3: Design of steel structures - Part 1-9: Fatigue.

EN 1993-2:2005. Eurocode 3: Design of steel structures - Part 2: Bridges.

Feldmann, M. et al. 2020. Neubewertung und Erweiterung des Kerbfallkataloges nach Eurocode 3 für eine zukunftsfähige Auslegung hochbeanspruchter Stahlkonstruktionen, AiF-DASt-FOSTA research project IGF-No. $19178 \mathrm{~N}$, final report.

Hanswille, G. \& Schubart, R. 2017. Entwurf der Talbrücke Rinsdorf. Stahlbau 86, Heft 8.

Hobbacher, A. 2014. Recommendations for fatigue design of welded joints and components, IIWDocument XIII-2151r4-07.

Holický, M. 2005. Basic statistical concepts and technique - Implementation of Eurocodes Handbook 2 Reliability Backgrounds. Leonardo da Vinci Pilot Project CZ/02/B/F/PP-134007.

Kuhlmann, U. \& Gölz, L. 2021. Praxisgerechte Gestaltung von Diagonalrohr-Anschlüssen im Stahl- und Verbundbrückenbau - Practice-oriented design of tubular bracings in steel and composite bridges. AiFDASt Final Report IGF-No. 20452N (in prep.).

Mang, F., Bucak, Ö. \& Klingler, J. 1987. Wöhlerlinienkatalog für Hohlprofilverbindungen. Versuchsanstalt für Stahl, Holz und Steine, Universität Karlsruhe, Studiengesellschaft für Anwendungstechnik von Eisen und Stahl, Düsseldorf.

prEN 1993-1-9. 2020. Eurocode 3: Design of steel structures - Part 1.9: Fatigue. Draft, European committee for standardization.

Sedlacek, G. 1984. Betriebsfestigkeitsnachweis für dynamisch beanspruchte Stahlkonstruktionen - DIN 18800 Teil 6. Research project No. 838000076. Institut für Bautechnik, Berlin.

Stahlbau Handbuch (Steel Construction Handbook). 1993. Für Studium und Praxis - Band 1 Teil A, Stahlbau-Verlagsgesellschaft mbH Köln.

Zirn, R. 1975. Schwingfestigkeitsverhalten geschweißter Rohrknotenpunkte und Rohrlaschenverbindungen. Dissertation. University of Stuttgart. 